\title{
Physio-biochemical and Molecular Responses of Mung Bean (Vigna radiata L. Wilczek) to Salt Stress
}

\author{
S. Subashree ${ }^{1}$, N. Sritharan ${ }^{2}$, M. Raveendran ${ }^{1}$, R. Poornima ${ }^{1}$, K. Dhivya ${ }^{1}$ and S. Rajesh ${ }^{1 *}$ \\ ${ }^{1}$ Department of Plant Biotechnology, CPMB \& B, Tamil Nadu Agricultural University, \\ Coimbatore, India \\ ${ }^{2}$ Department of Crop Physiology, Tamil Nadu Agricultural University, Coimbatore, India \\ *Corresponding author
}

\section{A B S T R A C T}

Keywords

Mung bean, Salt stress, Biochemical analysis, Molecular analysis, LEA proteins

Article Info

Accepted:

12 December 2020 Available Online: 10 January 2021
Soil salinity kindles a cascade of events in the normal functioning of the plant. Plant experience changes in the morphological, physiological and biochemical aspects in response to salt stress. In the current study, several experiments pertaining to the changes due to salt stress has been studied in Mung bean. Morphologically, a significant decrease in fresh weight of roots (1.89 folds) was observed. About 3.27 and 3 fold decrease in the Relative Water Content and Chlorophyll levels, respectively were observed in $300 \mathrm{mM}$ $\mathrm{NaCl}$ treated and control mung bean plants. Proline level increased to 2.69 folds at 24 hrs in stress imposed plants compared to control. Molecular level changes due to salt stress was analyzed by Semi-RT-qPCR analysis. Total RNA was isolated from the control and salt-stressed samples and cDNA synthesized. Expression analysis of Late embryogenesis abundant(LEA) protein coding genes, $\operatorname{VrLEA13}$ and $\operatorname{VrLEA26}$ revealed amplicons of around $190 \mathrm{bp}$ and $200 \mathrm{bp}$, respectively. This study creates an insight into the mechanism with which mung bean responds to salt stress by highlighting the significant variation in morpho, physio-biochemical and molecular responses.

\section{Introduction}

Pulses are rich sources of protein and hence are rightly pronounced as "Poor man's meat" and "rich man's vegetables". Vigna radiata L. (Green gram, Mung bean) is an important food legume crops native to India belonging to the family Fabaceae. It is a self-pollinated and a diploid crop $(2 \mathrm{n}=2 \mathrm{x}=22)$ with a genome size of 494-579Mbp.The short life span and nitrogen-fixing ability in the soil makes mung bean a valuable crop in most cropping systems (Somta and Srinives, 2007). Salinity stress is one of the most common abiotic stresses in the arid and semi-arid regions (Dutta et al., 2018).Salinity acts as a major environmental constraint that hampers the growth, development, and yield of the plant by altering the morphological, physiological, and biochemical attributes (Taji et al., 2002, Morant-Monceau et al., 2004 and Kandil et al., 2012). The first and foremost effects of salinity stress in pulses are reduction in root length, shoot length, germination percentage, 
fresh and dry weight of shoot and root, and chlorophyll content (Abdul-Baki and Anderson, 1973; Magwanga et al., 2018). Saline stress also induces oxidative stress resulting in the generation of Reactive Oxygen Species (ROS), which shows its mischievous effect on the intracellular structure and the cell membrane (Mudgal et al., 2010). Mung bean is known to be a saltsensitive legume crop (Quddus et al., 2012). Under hydroponic salt stress condition, mung bean's root length, shoot length, fresh weight, dry weight, and chlorophyll content were diminished when compared to contro (ElKafafi, 2015), whereas the proline and peroxidase content was increased (Ghosh et al., 2015). In Spinach, the total soluble sugar (TSS) content increased as a result of an increase in the salt concentration in the shooting medium (muchate et al., 2019). The present research focused on morphological, physiological, and biochemical adaptation of mung bean in high saline stress conditions. There are several proteins and transcription factors that aid the plants in overcoming abiotic stresses. LEA belongs to a class of proteins that helps the plant in battling stresses like temperature, drought, and salinity. Considering the above antagonistic impact of salinity stress on mung bean, it is important to develop a salt lenient assortment of mung bean which can be used by the farmers for cultivating under high saline conditions.

\section{Materials and Methods}

\section{Experimental materials}

Seeds of Mung bean variety CO (GG)8 werecollected from the Department of Pulses, Tamil Nadu Agricultural University, Coimbatore. This variety is a popular short duration ruling variety with moderate resistance to Mung Bean Yellow Mosaic Virus.

\section{Imposition of salt stress and Sample} collection

The seeds were sown in non-drainage plastic pots $(22.8 \mathrm{~cm} \quad X \quad 17.7 \mathrm{~cm})$ containing a sterilized mix of red and clay soil (1:1). After the emergence around two-leaf stage, the seedlings were irrigated with different $\mathrm{NaCl}$ concentrations viz.,0mM, $100 \mathrm{mM}, 150 \mathrm{mM}$, $200 \mathrm{mM}, 250 \mathrm{mM}$, and $300 \mathrm{mM} \mathrm{NaCl}$. The $\mathrm{pH}$ and Electrical Conductivity (EC) were checked. The samples were collected in different time intervals viz., $0^{\text {th }}$ hrs (Plant with no exposure of stress), $3^{\text {rd }} \mathrm{hr}, 6^{\text {th }} \mathrm{hr}, 9^{\text {th }} \mathrm{hr}$, $12^{\text {th }} \mathrm{hr}$ and $24^{\text {th }} \mathrm{hr}$, after which various physiological, biochemical, and molecular analyses were carried out.

\section{Morphological parameter analysis}

Followed by the imposition of salt stress, the mung bean seedlings were randomly selected from each treatment and washed thoroughly with distilled water. The length of the root, shoot, and leaf was measured in $\mathrm{cm}$, while the fresh and dry weights of the root and shoot were measured in grams.

\section{Seedling vigor index}

Seedling vigor index was calculated by using the below formula as reported by Abdul-Baki et al., 1973 expressed in whole number.

SVI $=($ Average plumule length + Average Radical lenghth $) \times$ Germiantion percentage

\section{Relative Water Content (RWC)}

The Relative water content estimation was done by Barrs and Weatherley(1962) method. Leaves from control and stress imposed plants were collected under different time interval. Initially, the fresh weight of the leaves was taken followed by the turgid weight by plating the leaves in Petri dishes containing distilled water soaking leaves for 6hours. The samples 
were kept in a hot air oven at $70^{\circ}$ Covernight and the dry weight was noted. The RWC was recorded using the formula

$\operatorname{RWC}(\%)=\frac{\mathrm{F}_{\mathrm{w}-} \mathrm{D}_{\mathrm{w}}}{\mathrm{T}_{\mathrm{W}}-\mathrm{D}_{\mathrm{w}}} \times 100$

Where,

"Fw" is the fresh weight,

"Dw" is the Dry weight

"Tw" is the turgid weight and

"RWC" is expressed in percentage (\%)

\section{Determination of chlorophyll content}

The Chlorophyll content determination was done by the Arnon method (1949). Fresh leaf samples were harvested from control and treated plants and ground using $80 \%$ chilled acetone and centrifuged at $3000 \mathrm{rpm}$ for 10 min. The supernatant was made up to a volume of $25 \mathrm{ml}$ with $80 \%$ acetone. The color absorbance of the solution was estimated for chlorophyll b at $645 \mathrm{~nm}$ for chlorophyll at $663 \mathrm{~nm}$. The total chlorophyll content was measured using the formula,

Chlorophyll content $=\frac{(20.2 \times \text { A645) }+(8.02 \times \text { A663) }}{1000 \mathrm{XW}} \times \mathrm{V}$

Where,

"W" is the fresh weight of the material "V" is the extraction volume and it is expressed in terms of $\mu \mathrm{g} \mathrm{g}^{1}$ fresh tissue

\section{Estimation of Peroxidase content}

The Peroxidase content was estimated by Sumner and Gjessing method (1943). Fresh leaf material $(0.5 \mathrm{~g})$ harvested from control and $\mathrm{NaCl}$ treated samples were homogenized with ice-cold phosphate buffer (pH-6.5) and centrifuged at $10,000 \mathrm{rpm}$ for $20 \mathrm{~min}$. The supernatant was taken and used for enzyme source. Each reaction mixture containing $1 \mathrm{ml}$ of ortho-dianisidine, $0.5 \mathrm{ml}$ of $\mathrm{H}_{2} \mathrm{O}_{2}, 1 \mathrm{ml}$ of phosphate, $2.4 \mathrm{ml}$ of distilled water, and the tubes were incubated at $30^{\circ} \mathrm{C}$. The reaction was stopped by adding $1 \mathrm{ml}$ of $\mathrm{H}_{2} \mathrm{SO}_{4}$. The absorbance was recorded at $430 \mathrm{~nm}$ by using GENESYS $^{\mathrm{TM}} \quad 40 / 50 \quad$ Vis/UV-Visible spectrophotometer and it was expressed in terms of $\mu \mathrm{Mg}^{-1} \mathrm{~min}^{-1}$.

\section{Estimation of Proline content}

Proline content was estimated according to the method of Bates (1973). Plant materials from control and treated samples were ground in $10 \mathrm{ml}$ of $3 \%$ sulpho-salicylic acid and centrifuged at $3000 \mathrm{rpm}$ for $10 \mathrm{~min}$. The supernatant was taken to this $2 \mathrm{ml}$ of acid ninhydrin (1.25 g of ninhydrin in $30 \mathrm{ml}$ of warm glacial acetic acid), $2 \mathrm{ml}$ of glacial acetic acid, $2 \mathrm{ml}$ of $6 \mathrm{M}$ orthophosphoric acid were added and the tubes were heated in a water bath $\left(65^{\circ} \mathrm{C}\right)$ for one hour. The reaction was terminated by placing the tubes in an ice bath, followed by $4 \mathrm{ml}$ of toluene was added to the test tube and mixed vigorously for 30 sec. The absorbance was recorded at520nm against a standard curve prepared using a known concentration of proline. The proline content was calculated by using the following formula and expressed in terms of $\mu \mathrm{g} / \mathrm{g}$.

$\mu$ mol proline $\mathrm{g}^{-1}$ fresh weight $=(\mu \mathrm{g}$ proline $\mathrm{ml}^{-1 \times} \mathrm{ml}$ of toluene/115.5) / ( $\mathrm{g}$ of sample)

\section{Estimation of Total soluble sugars}

Total soluble sugar was estimated according to the method Yemm and Willis (1954). $100 \mathrm{mg}$ fresh leaf tissue from control and $\mathrm{NaCl}$ treated samples were homogenized with $10 \mathrm{ml}$ of $80 \%$ ethanol followed by centrifugation. The supernatant was collected and the final volume of supernatant was made up to $10 \mathrm{ml}$ with ethanol $(80 \%)$. $1 \mathrm{ml}$ of sample was taken for analysis along with $1 \mathrm{ml}$ 
of distilled water and $4 \mathrm{ml}$ of anthrone reagent was added and kept in the water bath for $1 \mathrm{~min}$ at $70^{\circ} \mathrm{C}$. For an exothermic reaction, the test tubes were cooled in the air. The absorbance was recorded at $620 \mathrm{~nm}$ on GENESYS ${ }^{\mathrm{TM}}$ 40/50 Vis/UV-Visible spectrophotometer against a standard curve prepared using a known concentration of D-glucose and expressed in terms of $\mathrm{mg} \mathrm{g}^{-1} \mathrm{fw}^{-1}$.

\section{Estimation of Ascorbic acid}

The Ascorbic acid determination was done by the Omaye method (1979).0.5 g of leaf tissue from control and stress imposed samples were homogenized with 5\% tricarboxylic acid and centrifuged at $3500 \mathrm{rpm}$ for $20 \mathrm{~min}$ followed by the supernatant and was mixed with $0.2 \mathrm{ml}$ of DTCS reagent ( $3 \mathrm{~g}$ of $2,4 \mathrm{DNPH}, 0.4 \mathrm{~g}$ thiourea and $0.05 \mathrm{~g}$ of $\mathrm{CuSO}_{4}$ were dissolved in $9 \mathrm{~N}$ sulphuric acid and made up to the volume $100 \mathrm{ml}$ ) incubated at $37^{\circ} \mathrm{C}$ for 3 hours followed by $1.5 \mathrm{ml}$ of ice-cold sulphuric acid was added and the solution was kept at room temperature for $30 \mathrm{~min}$. The absorbance was recorded at 540nm GENESYS ${ }^{\mathrm{TM}}$ 40/50 Vis/UV-Visible spectrophotometer and the results were expressed as $\mu \mathrm{g} / \mathrm{mg}$ of protein.

\section{RNA isolation and Semi-quantitative reverse transcriptase (Semi-qRT-PCR) analysis}

Total RNA was extracted with TRIzol reagent, the concentration and quality of the RNA samples were assessed using a nanodrop (Genway Nano, Cole-Parmer, UK) and Agarose gel electrophoresis. To remove DNA contamination from RNA, DNaseI treatment (Promega) was carried out with the isolated RNA. The first-strand cDNA was synthesized using Thermo scientific cDNA synthesis kit. The VrLEA 13, VrLEA 26 genes were amplified by PCR using first-strand cDNA isolated from the seedling of salt-stressed $\mathrm{CO}$ (GG) -8 variety.

\section{Results and Discussion}

\section{Effect of $\mathrm{NaCl}$ stress on the plant growth paramters}

Our experiment showed that there was a significant reduction in the root, shoot, leaf length and leaf area with an increasing $\mathrm{NaCl}$ concentration over the control (Fig 1). A reduction in fresh weight and dry weight of roots was observed in the salt-stressed plants when compared with the water control (Fig 2a). In the case of shoot fresh as well as dry weight, there was no evident change observed between the treated and control plants (Fig.2b).

Leaf fresh weight increased only at moderate salinities but decreased significantly at high salt levels like 250 and $300 \mathrm{mM} \mathrm{NaCl}$ (Fig2c).Total leaf area per plant remained unchanged even up to $100 \mathrm{mM} \mathrm{NaCl}$ condition. On the other hand, beyond $100 \mathrm{mM}$ $\mathrm{NaCl}$ leaf area remained more or less stable (Fig3). The highest value of seedling vigor index (3870) was recorded with the $100 \mathrm{mM}$ $\mathrm{NaCl}$ treatment. The lowest seedling vigor index was recorded from Control (2825) (Fig 4).

\section{Effect of $\mathrm{NaCl}$ stress on physio-biochemical indices}

\section{Relative water content}

Relative water content is a very sensitive parameter of plant development which is impaired at slightly severe stress. At 24 hours, the plant was subjected to $100 \mathrm{mM} \mathrm{NaCl}$ stress showed 0.46 fold decreases in the relative water control levels when compared to the control, whereas the plant subjected to $300 \mathrm{mM} \mathrm{NaCl}$ shows a drastic decrease of 3.27 folds when compared to the control. This indicates that with increasing levels of $\mathrm{NaCl}$ there is a decline in the RWC levels (Fig5). 


\section{Chlorophyll content}

Leaf chlorophyll content decreased progressively with increasing salt levels. For control there were 3 fold decrease in the chlorophyll content in $300 \mathrm{mM} \mathrm{NaCl}$ treated at seedling stage for24hrs (Fig6).

\section{Peroxidase activity}

A similar trend was also observed after $\mathrm{NaCl}$ stress imposition, where the peroxidase activity in the seedling was drastically elevated $(2.78$ times) at $300 \mathrm{mM} \mathrm{NaCl}$ comparative to control (Fig 7).

\section{Proline content}

In our experiment with an increase in salinity a significant enhancement in proline activity,
2.69 fold increase in the control seedling (Fig8) was observed.

\section{Total soluble sugar content}

Total soluble sugars were gathered in moderately higher quantities at the increased salt level. In our experiment when compared to $0 \mathrm{mM} \mathrm{NaCl}$ at $0 \mathrm{hrs}$ and $300 \mathrm{mM} \mathrm{NaCl}$ at 24 hrs resulted in a 4.6 times increase in the leaf total soluble sugar content over water control (Fig 9).

\section{Ascorbic acid activity}

$\mathrm{NaCl}$ treatment for 9 hrs (100 and $150 \mathrm{mM}$ $\mathrm{NaCl}$ ) showed significant increases in the ascorbic acid content when compared to 0hrs and 24 hrs (Fig10).

Fig.1 Effect of various concentration of $\mathrm{NaCl}$ on the root, shoot and leaf length

of mung bean Seedling

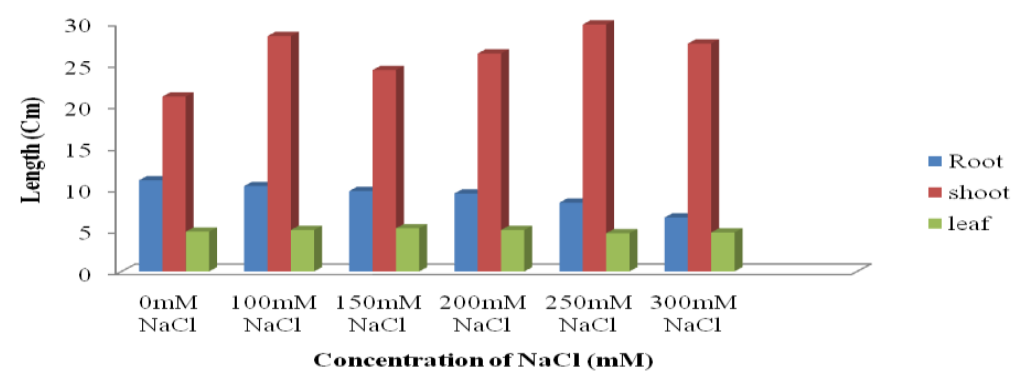

Fig.2 Impact of salinity stress on the fresh weight and dry weight of a) root, b) shoot and c) leaf mung bean seedling under different time interval

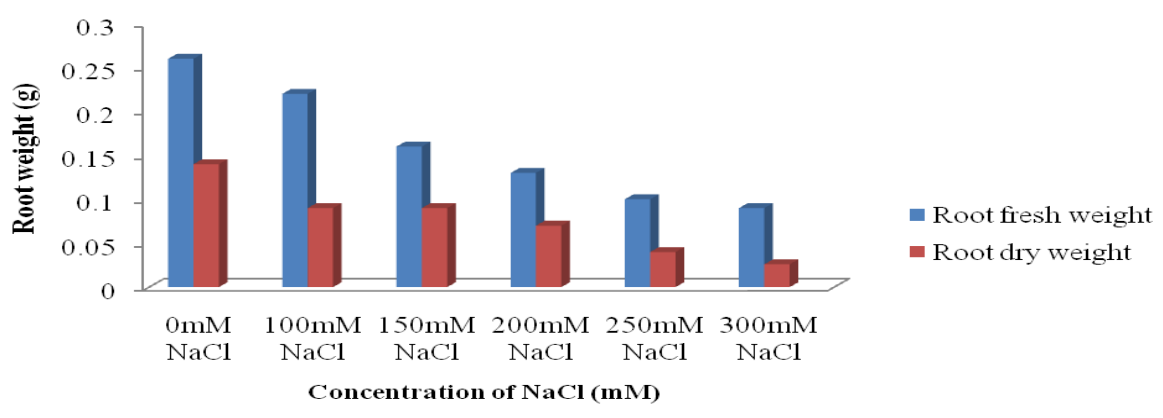

(a) 


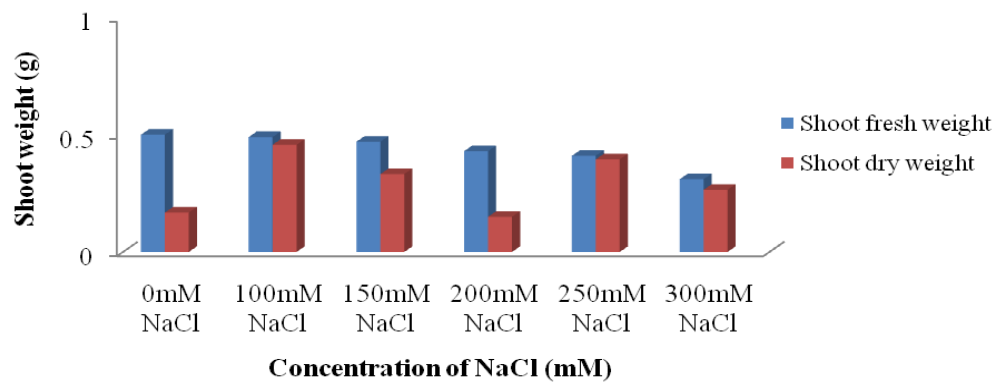

(b)

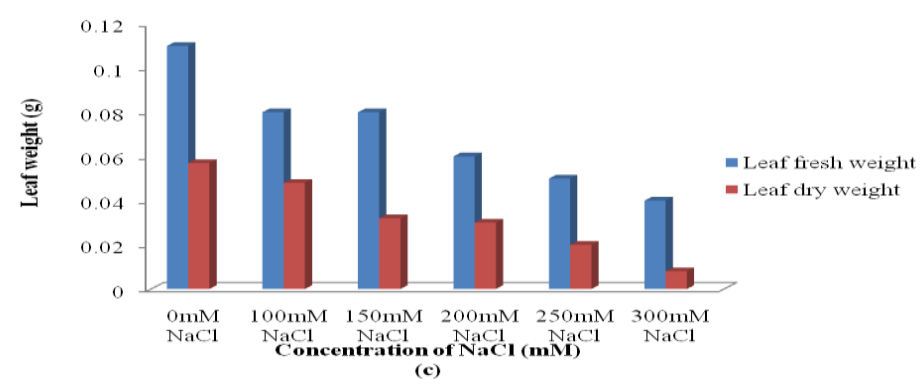

Fig.3 Impact of salinity stress on leaf area of mung bean seedling

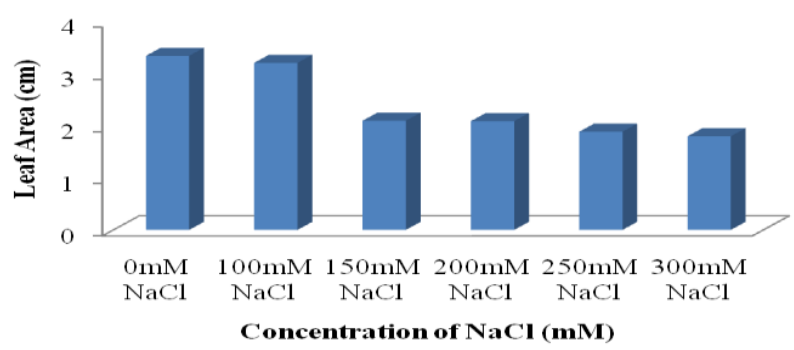

Fig.4 Average of seedling vigor index as affected by various concentration salinity stress of mung bean seedling

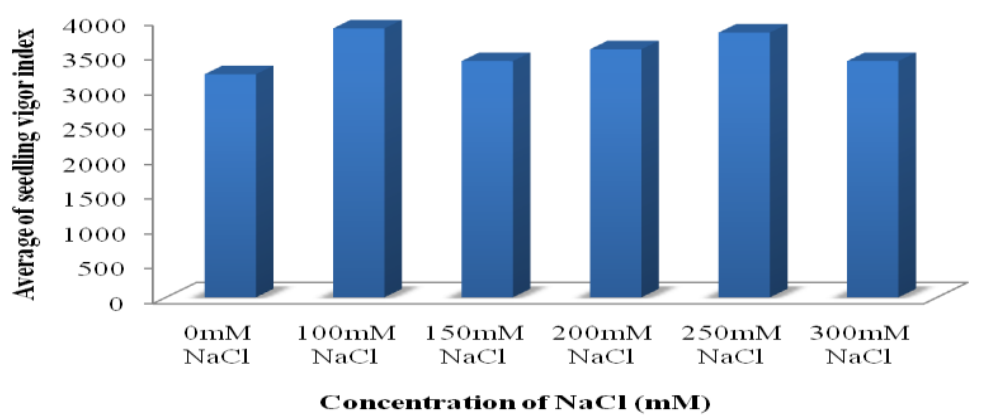


Fig.5 Effect of $\mathrm{NaCl}$ stress on Relative water content of mung bean seedling under different time intervals

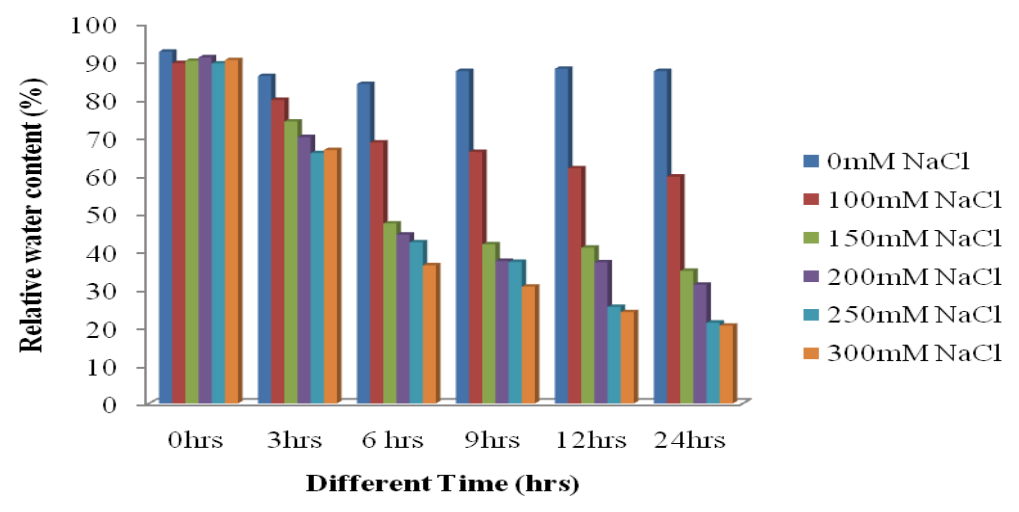

Fig.6 Effect of salinity stress on the total chlorophyll content of mung bean seedling under various time intervals

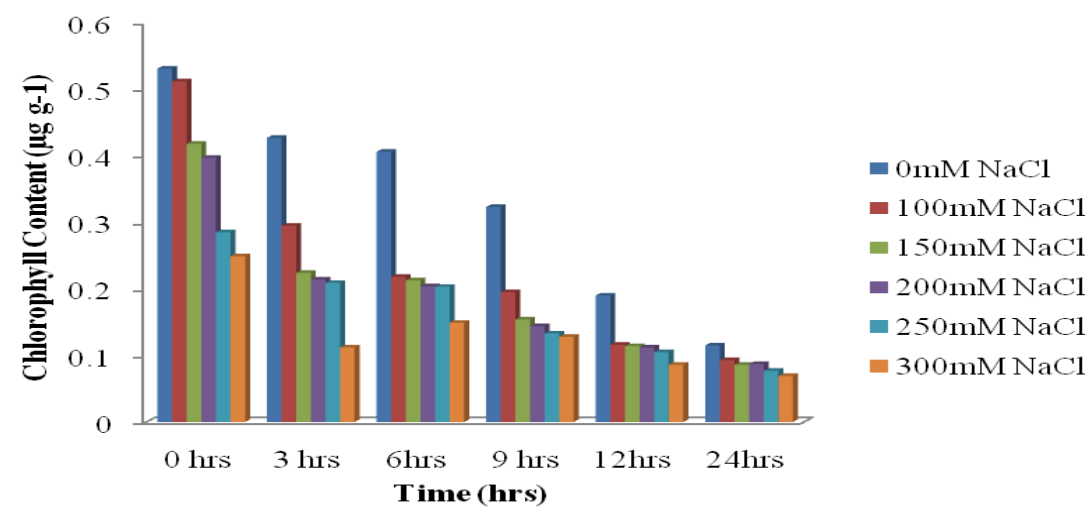

Fig.7 Impact of salinity stress on the accumulation of peroxidase content of mung bean seedling under different time intervals

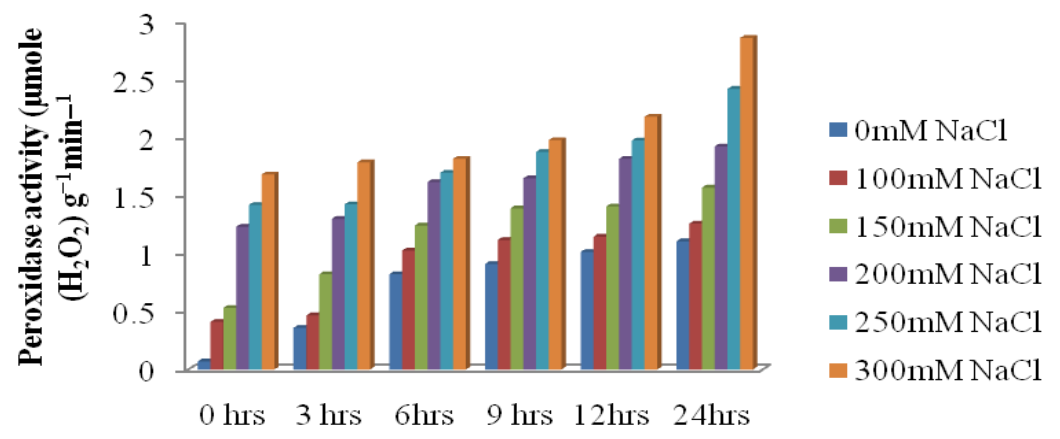

Time (hrs) 
Fig.8 Effect of salinity stress on the accumulation of total proline content of mung bean seedling under various time intervals

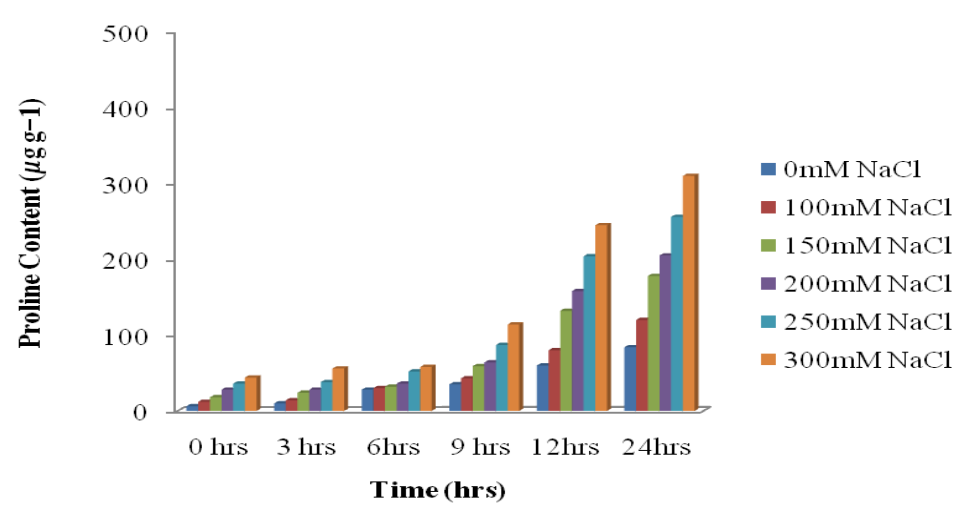

Fig.9 Impact of salinity stress on the accumulation of total soluble sugar content of mung bean seedling under different time intervals

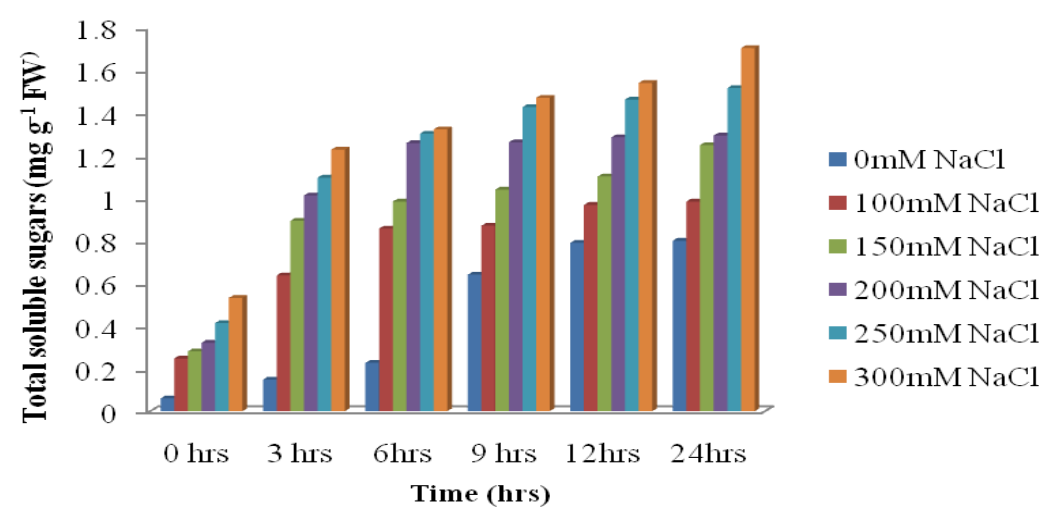

Fig.10 Impact of salinity stress on the accumulation of Ascorbic acid content of mung bean seedling under different time intervals

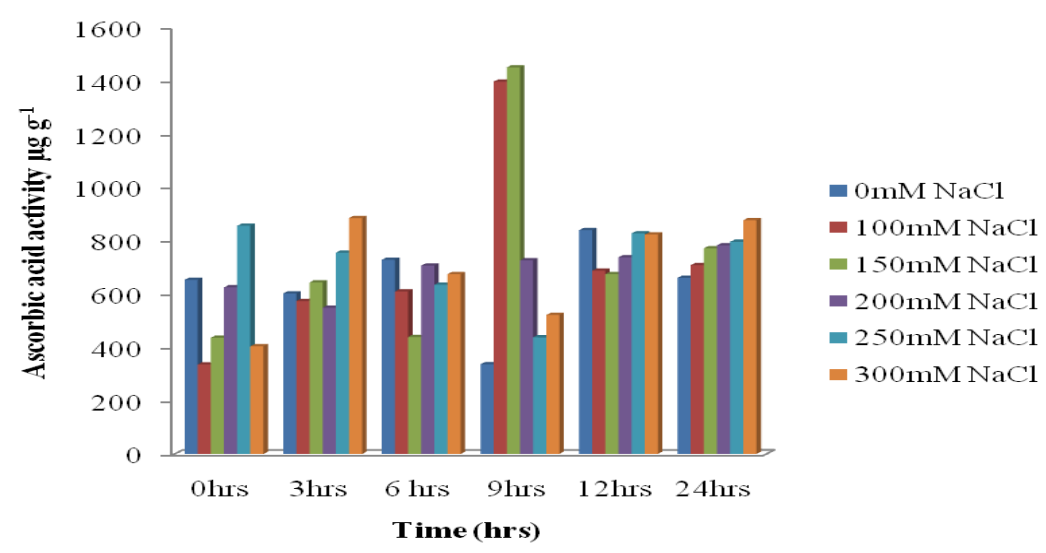


Fig.11 Total RNA profile of mung bean from control and stress imposed plants resolved on $1 \%$ Agarose gel; L-100 bp ladder; 1 - RNA from control plant; 2 to 6 - RNA from salt-treated plants

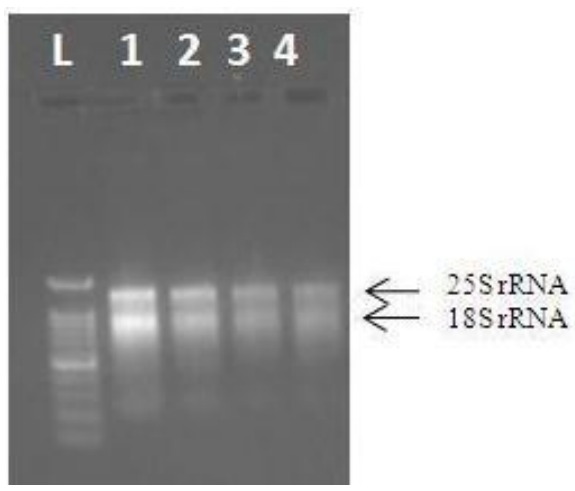

Fig.12 PCR amplification of mungbean cDNA for VrLEA 13 gene resolved on 1\% agarose gel; L-100 bp DNA ladder; 1 - Negative control; 2 to 4 - PCR amplified product of cDNA with VrLEA13 gene

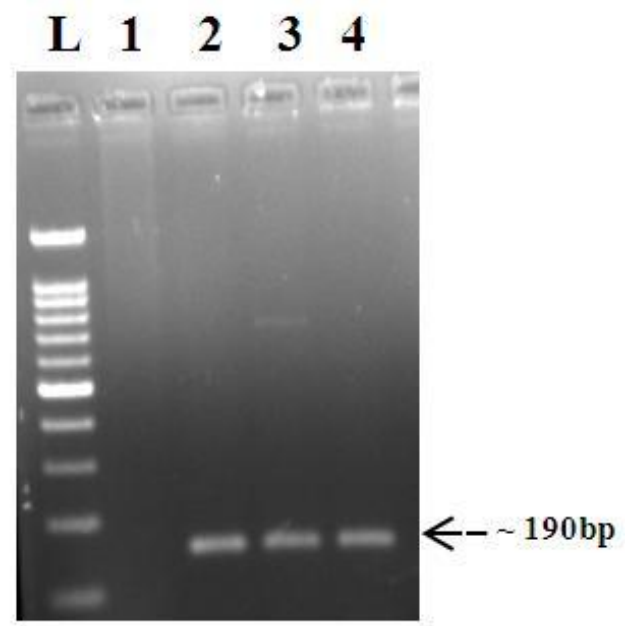

Fig.13 PCR amplification of mungbean cDNA for VrLEA 26 gene resolved on 1\% Agarose gel; L- 100bp DNA ladder; 1 - Negative control; 2 to 4 - PCR amplified product PCR of cDNA with VrLEA 26 gene

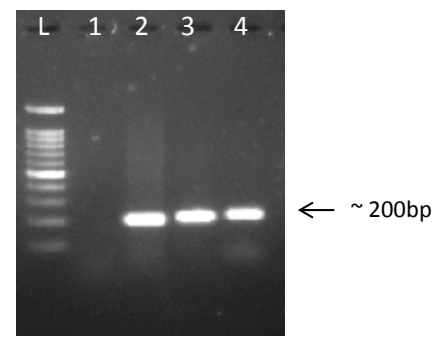

Expression analysis of $\operatorname{VrLEA13}$ and VrLEA26genes

Distinct rRNA banding patterns were 
observed in the total RNA profile of salt control and stressed samples (Fig11). Expression analysis revealed that the amplicon size of the genes VrLEA13 and $\operatorname{VrLEA26}$ were found to be around $190 \mathrm{bp}$ and 200 bp respectively (Fig.12 \& Fig 13).

\section{Stress induced altered morphological indices of mung bean}

The study showed a significant reduction in the root length with an increasing level of $\mathrm{NaCl}$, whereas the shoot and leaf lengths remain unaffected. The same reduction of this root, shoot as well as leaf length was observed by Ghosh et al., 2015.Salt stress caused lower intra-cellular water potential and water shortage around the root zone because of which roots neglected to uptake adequate water and supplements for satisfactory plant development (Kumar et al., 2012).Reduction in biomass under salinity was observed in perennial grass Cynodon dactylon (Hameed et al., 2008). Hence salt stress reduces the fresh weight and dry weight of mungbean seedling was confirmed in the present experiment. It has already been reported that a decrease in leaf area with the induction of salt stress in Cynodon dactylon. In our experiment, leaf area decreased with increasing $\mathrm{NaCl}$ concentration. This shows that salt stress highly affects the leaf area. It has already been reported that there was a decrease in seedling vigor index with the induction of salt stress in Brassica napus (Kandil et al., 2012). The present study experiment showed that the vigor index had increased by adding $100 \mathrm{mM}$ $\mathrm{NaCl}$ when compare to other salt concentration.

\section{Effect of salt stress on physio-biochemical parameters}

Salt stress causes membrane damage, ion toxicity, decrease the hydrolytic enzyme activity and increase the lipid peroxidation level, and may stimulate the ROS production level. In this study, the variety showed a decrease in leaf water potential with increasing the salt concentration at $300 \mathrm{mM}$. The same reduction in the leaf water potential was observed by Naz and Bano, 2013 at $200 \mathrm{mM}$ with the increase in salt stress. It has been reported that the mung bean plants developed under salinity stress demonstrated excess accumulation of leaf $\mathrm{Na}^{+}$and $\mathrm{Cl}^{-}$ bringing about increased ROS production and diminished photosynthetic activity and plant development (Panda et al., 2009). Our study showed a significant reduction in the chlorophyll content with increased level of $\mathrm{NaCl}$. The same reduction in the chlorophyll content with the increase in the salt stress was also observed by Roychoudhury et al., 2013.

During salt stress, peroxidase serves as a signal molecule plays an important role in plant defense mechanism. Hydrogen peroxide $\left(\mathrm{H}_{2} \mathrm{O}_{2}\right)$ substance is used as a stress marker for oxidative stress and is commonly influenced by abiotic stress. Salt stress increases the peroxidase content in stressed plants of mungbean in the present study. This observation corroborates findings of Dutta $e t$ al., 2018.

Under salinity stress, osmolyte like proline maintains cellular equilibrium through diffusion regulation and induces physiological process favorably ${ }^{[22]}$. The present study experiment showed that the leaf proline content increased consistently with increased salt concentration. Hence, the same accumulation of proline content increased uniformly under salt stress in mung bean was observed by Ghosh et al., ${ }^{[7]}$.

Total soluble sugars are mainly glucose and fructose was accumulated in relatively higher quantities in high salt level. A strong correlation between sugar accumulation and salt-tolerant has been earlier been reported in 
many species (Sumithra et al., 2006). Hence salt stresses significantly increase the total soluble sugar was shown in our experiment. Ascorbic acid is a significant antioxidant agent in photosynthetic and nonphotosynthetic tissues which responded straightforwardly with ROS in photosynthetic and non-photosynthetic tissues. The defensive role of ascorbic acid in plant cells from the unfavorable impact of salt stress was depicted by Yang and Guo, 2018.

LEA proteins are a major class of stress associated proteins with multiple roles in abiotic stress tolerance. Highly intrinsically disordered structures of dehydrin group of proteins under stress is reported in Vitisa murensis VamDHN3 (Xu et al., 2020) and several other plant species. Earlier studies from our group have revealed the possible function of Mungbean LEA proteins as a DNA binding protein with its hydrophilic nature similar to other Group 1 LEA proteins (Rajesh and Manickam, 2006). The present study indicated that two of the VrLEA genes expressed during the salt stress could possibly play a protective role during salinity stress.

In conclusion from this present study, it tends to be inferred that the utilization of salt unfavorably influenced the development as well as the metabolism of mungbean seedlings. High concentrations of salt induces stunted growth and loss in chlorophyll content and reduced the elongation of the leaf as well as oxidative damages by altering the antioxidant machinery leading to membrane damage through lipid peroxidation increasing the activity of proline, peroxidase and total soluble sugars in mung bean seedlings under different time intervals. Higher expression of VrLEA 13, VrLEA 26 gene in mung bean plants was observed when imposed with salt stress. Since few studies have simulated the conditions of following salt stress in the plant ecosystem, more studies are needed in the future to understand the effect of salt stress.

\section{Acknowledgement}

The authors gratefully acknowledge the Director, Centre for Plant Molecular Biology and Biotechnology for providing enormous facilities during the course of investigation.

\section{References}

Abdul-BakiA, Anderson J. D. Vigor determin ation in soybean seed by multiple criteria. Crop science, 1973; 13(6): 630-633.

Ahmad P, Prasad M. N. V. (Eds.) Environmental adaptations and stress tolerance of plants in the era of climate change. Springer Science\& Business Media,2011.

Arnon DI. Copper enzymes in isolated chloroplasts. Polyphenoloxidase in Beta vulgaris. Plant physiology, 1949; 24(1): 1.

Barrs HD, Weatherley PE.A re-examination of the relative turgidity technique for estimating water deficits in leaves. Australian journal of biological sciences, 1962; 15(3):413-428.

Bates LS, Waldren RP, Teare ID. Rapid determination of free proline for water-stress studies. Plant and soil,1973;39(1): 205-207.

Dutta T, Neelapu NRR, Wani SH, Challa S. Response of pulses to drought and salinity stress response: a physiological perspective. In Pulse improvement.Springer,Cham,2018; 77-98.

Ghosh S, Mitra S, Paul A. Physiochemical studies of sodium chloride on mungbean (Vigna radiata L. Wilczek) and its possible recovery with spermine and gibberellic acid. The Scientific World Journal,2015.

Hameed M, Ashraf M. Physiological and 
biochemical adaptations of Cynodon dactylon (L.) Pers. from the Salt Range (Pakistan) to salinity stress. Flora-Morphology, Distribution, Functional Ecology of Plants,2008; 203(8): 683-694.

El-Kafafi ESH, Helal AG, El Hafnawy SF, Flaah RFEL. Characterization and evaluation of some mungbean genotypes for salt tolerance. World Applied Science, 2015;33(3): 360370.

Kandil AA, Arafa A. A, Sharief AE, Ramadan AN. Genotypic differences between two mungbean varieties in response to salt stress at seedling stage. International Journal of Agriculture Sciences, 2012; 4(7): 278.

Kumar BS, Prakash M, Narayanan S, Gokulakrishnan J.Breeding for salinity tolerance in mungbean. APCBEE Procedia, 2012; 4: 30-35.

Magwanga RO, Lu p, Kirungu, JN, Lu H, Wang $X$, Cai $X$, and Liu $F$. Characterization of the late embryogenesis abundant (LEA) proteins family and their role in drought stress tolerance in upland cotton. BMC genetics, 2018;19(1): 6.

Morant-Manceau A, Pradier E, Tremblin G. Osmotic adjustment, gas exchanges and chlorophyll fluorescence of a hexaploid triticale and its parental species under salt stress. Journal of plant physiology, 2004;161(1):25-33.

Muchate NS, Rajurkar NS, Suprasanna P, Nikam TD. $\mathrm{NaCl}$ induced salt adaptive changes and enhanced accumulation of 20-hydroxyecdysone in the in vitro shoot cultures of Spinacia oleracea (L.). Scientific Reports, 2019; 9(1):1-10.

Mudgal V, Madaan N, Mudgal A. Biochemical mechanisms of salt tolerance in plants: a review. International Journal of Botany,2010;
6(2):136-143.

$\mathrm{Naz}$ R,Bano A. Influence of exogenously applied salicylic acid and plant growth promoting rhizobacteria inoculation on the growth and physiology of sunflower (Helianthus annuus L.) under salt stress. Pakistan Journal of Botany, 2013;45(2):367-373.

Omaye ST, Turnbull JD, Sauberlich HE. Selected methods for the determination of ascorbic acid in animal cells, tissues, and fluids. In Methods in enzymology,1979; 62: 311.

Panda SK, Khan M. H. Growth, oxidative damage and antioxidant responses in greengram (Vigna radiata L.) under short-term salinity stress and its recovery. Journal of Agronomy and Crop Science, 2009; 195(6):442-454.

Quddus MA, Rashid MH, Hossain MA, Naser HM, Mian JA. Integrated nutrient management for sustaining soil Fertility through chickpea-mungbeant. aman Cropping pattern at madaripur region. Bangladesh Journal of Agricultural Research,2012; 37(2): 251-262.

Rajesh, S., and Manickam, A. Prediction of functions for two LEA proteins from mung bean. Bioinformation, 2006 1(4), 133-138.

Roychoudhury A, Ghosh S. Physiological and biochemical responses of mungbean (Vigna radiata L. Wilczek) to varying concentrations of cadmium chloride or sodium chloride. Unique Journal of Pharmaceutical and Biological Sciences, 2013; 1: 11-21.

Somta P, Srinives P. Genome research in mungbean (Vigna radiata (L.) Wilczek) and blackgram (V. mungo (L.) Hepper). Science Asia,2007; 33 (11): 69-74.

Sumithra K, Jutur PP, Carmel BD, Reddy AR. Salinity-induced changes in two 
cultivars of Vigna radiata: responses of antioxidative and proline metabolism. Plant Growth Regulation, 2006; 50(1): 11-22.

Sumner JB,Gjessing EC. A method for the determination of peroxidase activity, Archives of Biochemistry and Biophysics, 1943;2(3):291.

Taji T, Ohsumi C, Iuchi S, Seki M, Kasuga M, Kobayashi M, Shinozaki K. Important roles of drought-and cold-inducible genes for galactinol synthase in stress tolerance in Arabidopsis thaliana. The Plant Journal,2002; 29(4): 417-426.

Xu M, Tong Q, Wang Y, Wang Z, Xu G, Elias G. K, Liang Z. Transcriptomic analysis of the grapevine LEA gene family in response to osmotic and cold stress reveals a key role for VamDHN3. Plant and Cell Physiology,2020; 61(4): 775-786.

Yang Y, Guo Y. Unraveling salt stress signaling in plants. Journal of Integrative Plant Biology, 2018;60(9): 796-804.

Younis, M. E, Hasaneen MN, Kazamel AM. Exogenously applied ascorbic acid ameliorates detrimental effects of $\mathrm{NaCl}$ and mannitol stress in Vicia faba seedlings. Protoplasma, 2010; 239(14): 39-48.

Yemm EW, Willis A. The estimation of carbohydrates in plant extracts by anthrone. Biochemical journal, 1954;57(3): 508-514.

\section{How to cite this article:}

Subashree, S., N. Sritharan, M. Raveendran, R. Poornima, K. Dhivya and Rajesh, S. 2021. Physio-biochemical and Molecular Responses of Mung Bean (Vigna radiata L. Wilczek) to Salt Stress. Int.J.Curr.Microbiol.App.Sci. 10(01): 853-865.

doi: https://doi.org/10.20546/ijcmas.2021.1001.104 